\title{
Analytic Signal Depth from High Resolution Aeromagnetic Data over the Gongola Basin Upper Benue Trough Northeastern Nigeria
}

\author{
*11MUSA, H, ${ }^{2}$ BASSEY, NE; ${ }^{1}$ BELLO, R \\ ${ }^{*}$ Department of Physics, Federal University of Kashere, Gombe state, Nigeria. \\ ${ }^{2}$ Department of Geology, Akwa Ibom state University, Mkpat Enin, Uyo, Nigeria. \\ *Corresponding Author Email: hayatudeenmusa@fukashere.edu.ng; Tel: +234 8030919526
}

\begin{abstract}
The study of high-resolution aeromagnetic data was carried out over the Gongola basin, upper Benue trough, northeastern Nigeria, for analytic signal depth determination. Total intensity magnetic map obtained from the data using the Oasis Montaj ${ }^{T M}$ programming software was used to get the residual map by polynomial fitting, from where the analytic signal was obtained with the use of anomaly width at half the amplitude $\left(\mathrm{X}_{1 / 2}\right)$. This was used to carry out depth estimations over the study area. The results showed that it peaks over the magnetic structure with local maxima over its edges (boundaries or contact), and the amplitude is simply related to magnetization, likewise results also showed that the depth estimates were in the range of 1.2 to $5.9 \mathrm{~km}$ and were calculated for contact, dyke/sill and horizontal cylinder respectively. The lowest values are from DD profiles, while the highs are from AA profiles. This work is important in identifying dykes, contacts and intrusives over an area.
\end{abstract}

\section{DOI: https://dx.doi.org/10.4314/jasem.v25i4.15}

Copyright: Copyright $(0) 2021$ Musa et al. This is an open access article distributed under the Creative Commons Attribution License (CCL), which permits unrestricted use, distribution, and reproduction in any medium, provided the original work is properly cited.

Dates: Received: 14 February 2021; Revised: 26 March 2021; Accepted: 12 April 2021

Keywords: Analytic signal, Aeromagnetic Data, Gongola Basin, Oasis Montaj, Profiles

High-resolution aeromagnetic data collected over the Gongola basin were analyzed for analytic signal depth using the Oasis Montaj ${ }^{T M}$ programming software. Residual map of the region investigated was generated by polynomial fitting from where the analytic signal was obtained using the anomaly width at half the amplitude $\left(\mathrm{X}_{1 / 2}\right)$, this was used to carry out depth estimations over the region investigated. The region is located between longitude $11^{\circ} 00^{\prime}-12^{0} 00^{\prime} \mathrm{E}$ and Latitude $10^{\circ} 00^{\prime}-11^{0} 00^{\prime} \mathrm{N}$, which is the Gongola trough, a division of the upper Benue trough which is also a sub set of the Benue trough, a Cretaceous sedimentary basin, trending in N-S direction. The Benue trough is generally said to have formed from a ridge- ridge-ridge structure which existed at the site of the present day Niger Delta in the early Cretaceous times (Bassey et al., 2012), with arms as the Gulf of Guinea (R), the South Atlantic (R) and the Benue Arm $(\mathrm{R})$. The drainage feature of this region is characterized by the Gongola River which source is from the north central highlands composed of crystalline rocks. Well known municipalities in the region are Gombe, Dukku, Akko, Kaltungo and Billiri. Studies on the progression of the region investigated by Abubakar et al. (2010) revealed that the evolution of the area occurred in three stages. First, there were mantle upwelling which resulted in crustal stretching and thinning, followed by a block faulting and finally the emplacement of basic igneous material in the crust. Epuh et al. (2011) researched on the basement depth estimation using second vertical derivative data as input anomaly profile in the Gongola Basin. Their findings showed depths of $5.2 \mathrm{~km}$ for the SE part and $7.0 \mathrm{~km}$ for the NE part. Utilizing multivariate statistical analysis of residual gravity anomalies, Epuh et al. (2012) analyzed the Gongola Basin for hydrocarbon prospects. In their work on the downward continuation of residual Gravity anomalies using the integrated approach with density log, Epuh et al. (2014) deduced that the upper and lower depth limits of anomalous mass were at $2015 \mathrm{~m}$ and $2017 \mathrm{~m}$ respectively. Research by Mamman et al. (2010) on clay mineralogy and paleodepositional environments of Late Cenomanian-Turonian sediments in the Yola arm, upper Benue Trough, Northeastern Nigeria revealed the age and sequence of deposition within that period. Working on the Geology and tectonosedimentary disposition of the Bima sandstone of the other arm of upper Benue Trough (Nigeria) by Haruna et al. (2012), their results showed the implications for sandstone-hosted Uranium deposits. The aim of this research was to analyze high resolution aeromagnetic data obtained over the Gongola Basin using the Oasis Montaj TM software, in order to get the total magnetic intensity map as well as the residual map from where the analytic signal was obtained using the anomaly 
width at half the amplitude $\left(\mathrm{X}_{1 / 2}\right)$ was used to carry out depth estimations over the study area.

Geology of the area: The research area is the Gongola basin which is the western sector of the Upper Benue Trough, a N-S trending structure and a sub set of the Benue trough. Geologically, the basin has Cretaceous and Tertiary sedimentary rocks which include the Bima sandstones, Yolde formation, Pindiga formation, Gombe sandstones and the Kerri-Kerri formation respectively, with Precambrian basement gneisses being minor and are found at the eastern margin of the study area as shown in figure 1. The Cretaceous sediments made up to $5-6 \mathrm{~km}$ thick, the Tertiary Kerri-Kerri Formation (an iron rich sandstone formation) is an exclusively continental sequence derived from a Cretaceous sedimentary terrain and lay uncomfortably on the Gombe sandstone.

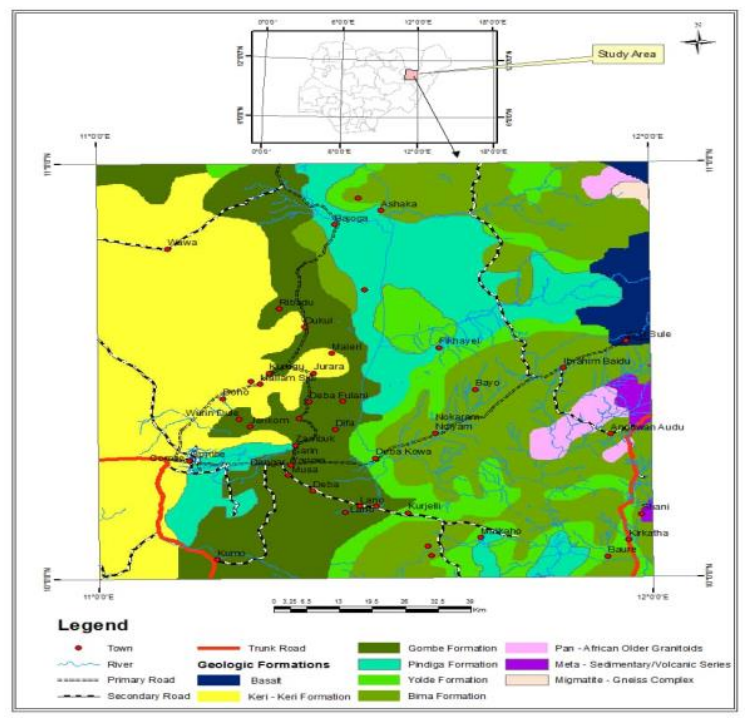

Fig 1. Geologic map of the study area.

\section{MATERIALS AND METHOD}

The high resolution aeromagnetic data utilized in this study were acquired for Nigeria Geological Survey Agency in 2010 as major aspect of nationwide geological survey by Fugro international. The data utilized for this study has the specifications of terrain clearance of $80 \mathrm{~m}$, flight line spacing of $500 \mathrm{~m}$ and tie line spacing of $5000 \mathrm{~m}$. The sheets with the index numbers 131,132, 152 and 153 were utilized for this work. The data was processed to generate the total magnetic intensity map (figure 2), and residual map (figure 3), utilizing the regional - residual separation of the polynomial fitting, where the regional is matched with a mathematical (polynomial) of low order to expose the residual features as random errors, from where analytic signal map was generated for depth determination. In recent time, the analytic signal technique has been vital in the interpretation of potential field data. Analytic signal is essentially a technique that utilizes Hilbert transformation and fast Fourier transforms of source field. Nabugian et al. (2005) developed the notion of 2-D analytic signal or energy envelope of magnetic anomalies. They demonstrated that the shape of the analytic signal of contacts and sheets were independent of the direction of magnetization and the local geomagnetic field. In their work, Roest et al. (1992) demonstrated that this was valid for any 2-D magnetic anomalies. As depicted by MacLeod et al. (1993), analytic signal can be expressed by equation (1), to such an extent that the square root of the squared sum of the vertical and the two orthogonal derivatives of the magnetic field are:

$$
\frac{|A(x, y, z)|=}{\sqrt{\left(\frac{d T}{d x}\right)^{2}+\left(\frac{d T}{d y}\right)^{2}+\left(\frac{d T}{d z}\right)^{2}}}
$$

The horizontal and vertical derivatives of the magnetic field are Hilbert transform pairs of each other (Nabigian, 1984). Analytic signal can now be calculated easily with commonly available computer software. The fast Fourier transforms technique was used in calculating the derivatives, for a 2-D magnetic contact at $(\mathrm{x}=0)$ and at depth $(\mathrm{h})$ the analytic signal anomaly is described by the expression of Nabigian, (1984) where:

$$
|A(x)|=\alpha \frac{1}{\left(h^{2}+x^{2}\right)^{\frac{1}{2}}}
$$

Where $\alpha$ is the amplitude factor and may be represented mathematically as in eqn 3 .

$$
, \alpha=2 M \sin d\left(1-\cos ^{2}(I) \sin ^{2}(A)\right)
$$

Where $\mathrm{h}=$ depth to the top of the contact, $M=$ strength of magnetization; $d=\operatorname{dip}$ of the contact; $I=$ inclination of the magnetization vector; $A=$ the direction of magnetization vector.

Equation (2) is for a dyke/sill shape function in which all the directional terms are contained in the amplitude factor $\alpha$, which is a constant. Therefore, only the amplitude of the analytic signal is influenced by the vector component of the model. The analytic signal shape relies on the depth alone. The signal exhibits maxima over magnetization contrast, independent of the ambient magnetic field and source magnetization direction. Equations also exist for other models such as thin sheet and horizontal cylinder.

\section{RESULTS AND DISCUSSION}

The Total Magnetic Intensity (TMI) map of the study area (figure 2) shows anomalies of high and low 
magnetic intensity values of 226 to $-107.6 \mathrm{nT}$ with dominant NE-SW trends. The dominant long wavelength anomalies with spatial scales of several kilometres are certainly due to deep seated basement under the basin. The map shows that the area is composed of different magnetic region. The regions are distinguished on the basis of the variation of the intensity of magnetic response. The north-eastern side is characterised by low magnetic anomalies, while the central part is characterised by highs. In this work, data was residualized (i.e. removal of the regional) leaving only the residual so as to obtain a magnetic response from the upper-crust of the earth comprising of the basement and sedimentary unit. The residual anomaly map (figure 3) shows magnetic anomalies similar to that of the TMI map in Figure 2. The anomalies of 260.9 to $-95.7 \mathrm{nT}$ exist as a sequence of areas of magnetic highs and lows. The dominant trend is in the NE-SW direction, which is related to the Pan Africa trend. The long wavelength features are undoubtedly due to very deep basement source and are referred to as regional. Small amplitude short wavelengths anomalies are superimposed on these large features.

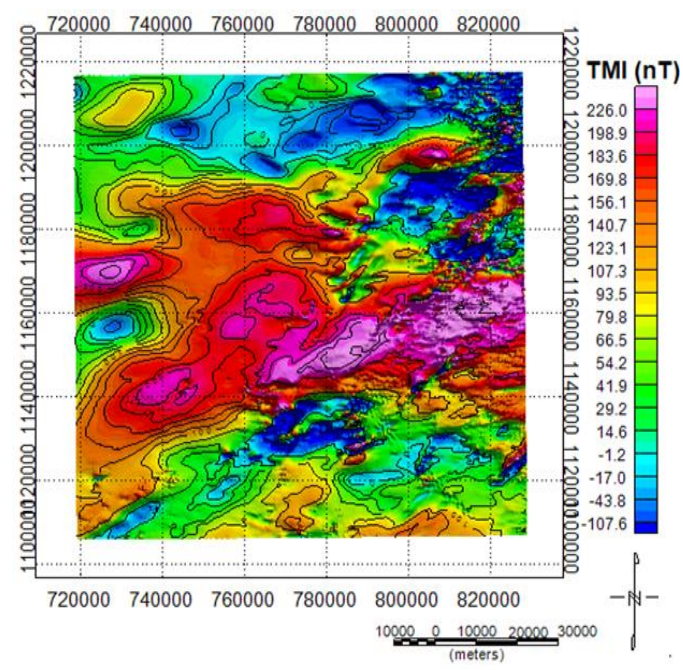

Fig 2. Total magnetic intensity map of the study area

Using the analytic signal anomaly width at half the amplitude $\left(\mathrm{X}_{1 / 2}\right)$, Roest et al. (1992) and Alabi et al., (2018) determined the depth to the magnetic sources of the analytic signal shape. The expression in equation (4) can be derived directly from equation (2)

$$
x_{1 / 2}=2 \sqrt{3 h}=3.46 h
$$

Also, MacLeod et al. (1993) took the approach of using the anomaly width at half the amplitude $\left(\mathrm{X}_{1 / 2}\right)$ of the analytic signal anomaly to determine the depth. This approach is observed to be better, in that the inflexion points occur higher up the flanks of the anomaly and therefore should be less susceptible to interference from neighboring anomalies. For a contact, the second derivative of equation 2 with respect to $\mathrm{x}$ produces the following result:

$$
x_{i}=\sqrt{2 h}=1.414 h
$$

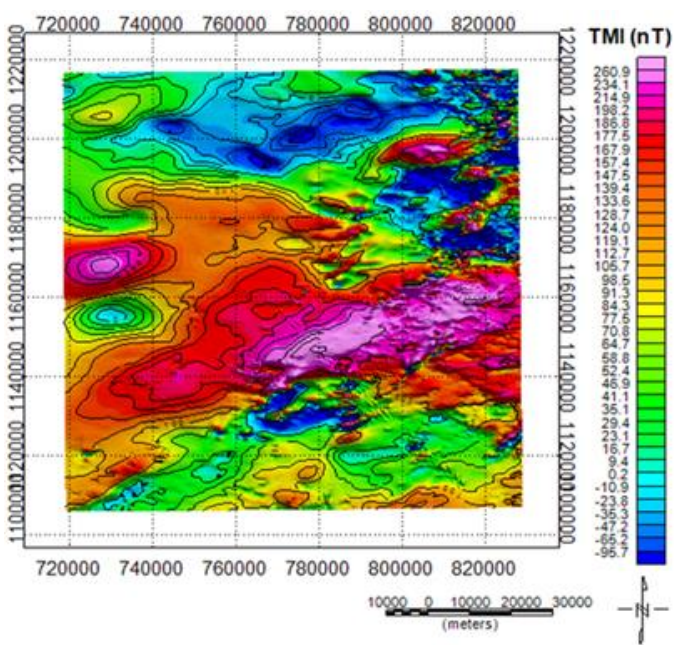

Fig 3. Residual map of the study area.

Note that using the width at half the amplitude and assuming a contact model, the true depth for dyke / sill bodies will be 1.73 times the modeled depth, and the true depth for a cylindrical body will be 2.25 times the modeled depth. In contrast, using the distance between inflexion points the true depth for a dyke will be 1.24 times the modeled depth, and the true depth of a cylindrical source will be 1.41 times the modeled depth.

From the above, it was concluded to assume a contact model when working with more regional data. In the worst case of a very thin dyke or sill, the contact model will underestimate the depth by $18 \%$. Both the dyke and the sill model will overestimate the depth - like bodies whose width approaches its depth. Vertical cylinder models can be rejected based on the fact that they produce a single isolated solution, and cylinders were rare. In map format, applying a simple $3 \mathrm{X} 3$ Laplacian filter to the analytic signal of gridded data will produce curvature map from which inflexion points are mapped by the zero contour.

From the Laplacian map, depths can be estimated by measuring the widths of the anomalies and applying the factors in Table 1. The main advantages of analytical signal method of depth determination are that, the magnetic field and magnetic source parameters need not be known or assumed. Likewise, since no reduction to the pole is required in 
computation of analytical signal, it is often useful at low magnetic latitudes (Keating and Sailhac, 2004).

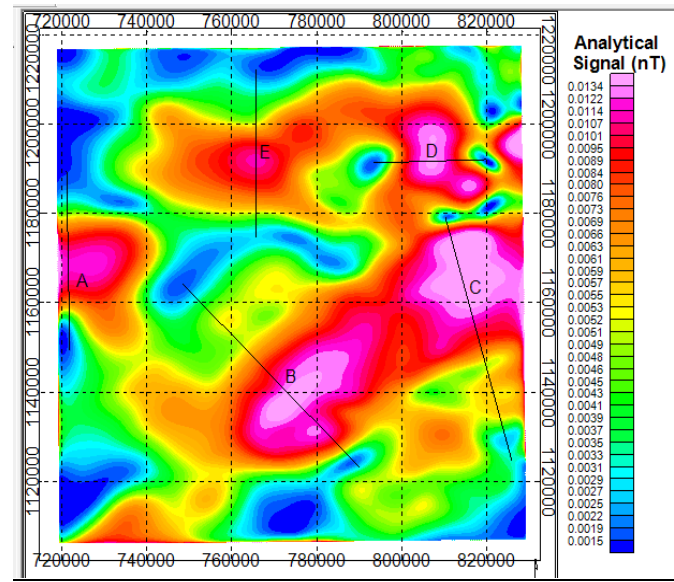

Figure (4a). Analytic signal map of the study area, showing where signals were picked for analysis

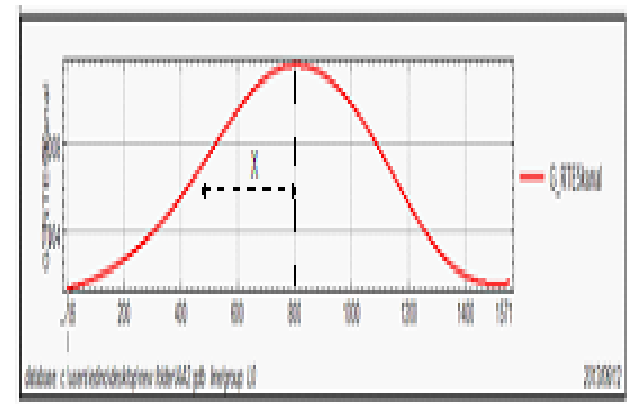

$\mathrm{AA}=320=9073.7 \mathrm{~m}$ (to scale)

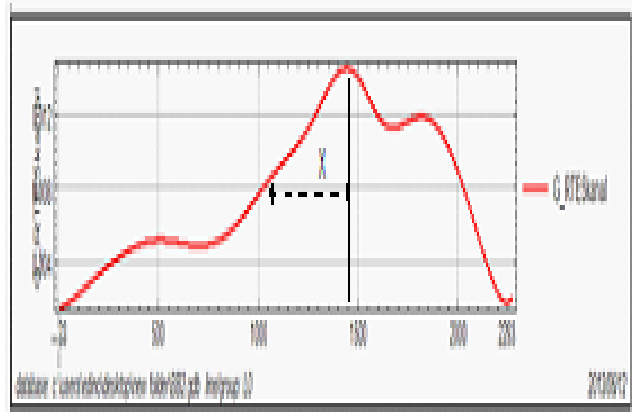

$\mathrm{BB}=400=8290.16 \mathrm{~m}$ (to scale)

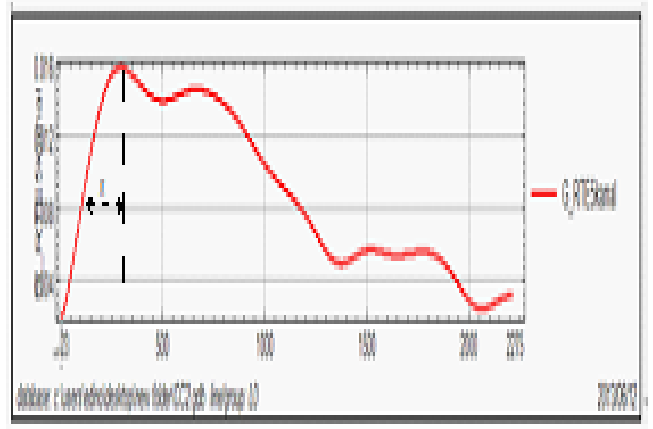

$\mathrm{CC}=275=7326.8 \mathrm{~m}$ (to scale)

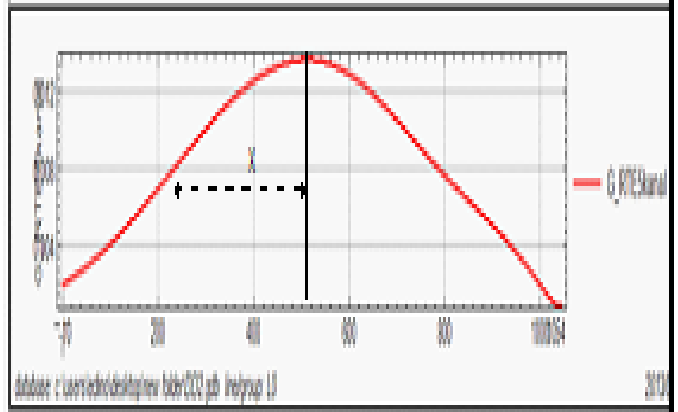

$\mathrm{DD}=260=6109.02 \mathrm{~m}$ (to scale)

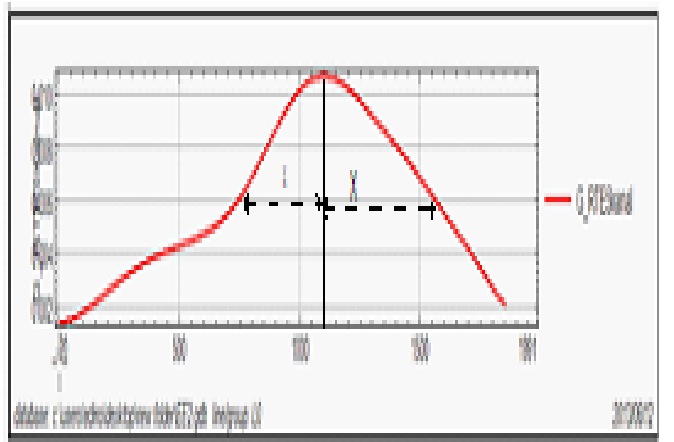

$\mathrm{EE}=350=6951 \mathrm{~m}$ (to scale)

Fig (4b). Analytic signal profile of the study area. (AA-EE)
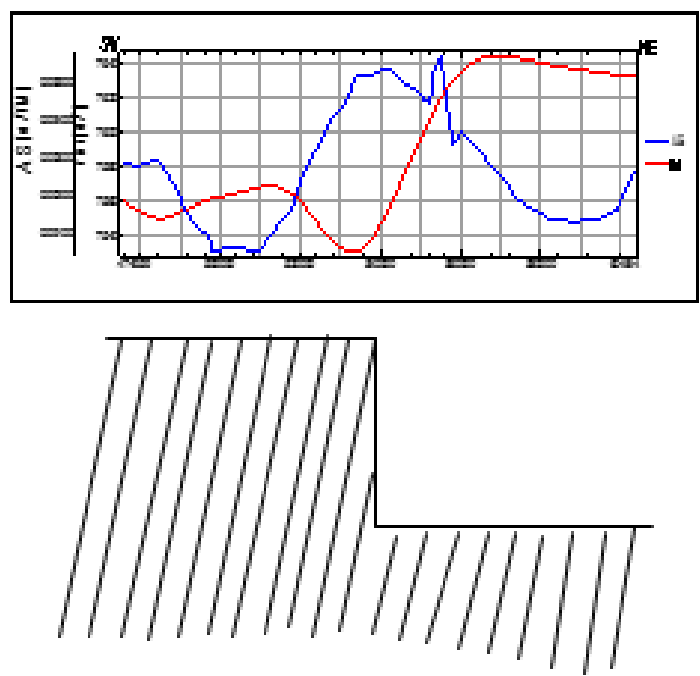

Fig 5. Example of contact determination using analytic signal (Top). Note how the analytic signal (blue line) peaks over the inflexion point of fault signature (red line). Below: Fault geometry.

Table1. Summary of the Two Approaches of determining depth from analytic anomalies (Adopted from MacLeod et al., 1993)

\begin{tabular}{lll}
\hline $\begin{array}{l}\text { Source } \\
\text { geometry }\end{array}$ & $\begin{array}{l}\text { Distance between } \\
\text { inflexion points }\end{array}$ & $\begin{array}{l}\text { Width at half } \\
\text { the amplitude }\end{array}$ \\
\hline $\begin{array}{l}\text { Contact } \\
\text { Dyke/sill }\end{array}$ & $1.414 \mathrm{~h}$ & $3.46 \mathrm{~h}$ \\
$\begin{array}{l}\text { Horizontal } \\
\text { Cylinder }\end{array}$ & $1.155 \mathrm{~h}$ & $2 \mathrm{~h}$ \\
\hline
\end{tabular}


Table 2. Result of depth determination for contact, dyke/sill and horizontal cylinder for profiles AA-EE, of the study area, from analytic signal

\begin{tabular}{lllll}
\hline Source & $\begin{array}{l}\text { Width at half } \\
\text { the amplitude } \mathrm{x} x \\
(\mathrm{~m})\end{array}$ & $\begin{array}{l}\text { Depth }(\mathrm{m}) \\
\text { for contact } \\
=\mathrm{x} / 3.46\end{array}$ & $\begin{array}{l}\text { Depth }(\mathrm{m}) \text { for } \\
\text { Dyke/sill } \\
=\mathrm{x} / 2\end{array}$ & $\begin{array}{l}\text { Depth }(\mathrm{m}) \\
\text { Horizontal } \\
\text { Cylinder } \mathrm{x} / 1.533\end{array}$ \\
\hline $\mathrm{AA}$ & 9073.7 & 2622.46 & 4536.85 & 5918.92 \\
$\mathrm{BB}$ & 8290.16 & 2396 & 4145.08 & 5407.80 \\
CC & 7326.8 & 2117.57 & 3663.4 & 4779.38 \\
DD & 6109.02 & 1765.61 & 3054.51 & 3985.01 \\
EE & 6951 & 2008.96 & 3475.5 & 4534.25 \\
\hline
\end{tabular}

In this work, data was transformed to its analytical signal to enable determination of basement texture and depths. The analytical signal peaks over the inflexion points from which depths were determined (Figure $4 b$ ). It should however be stated that the total field intensity data was slightly upward continued to $3 \mathrm{~km}$ to remove any artificial contaminations before application of the filter. The analytic signal map of the region investigated showed prominent features, this was the magnetic response from both sedimentary section and the basement. The analytic signal map showed intensity color range of $0.0015 \mathrm{nT}$, represented in blue color which correspond with the thick sedimentary section and 0.0134 nT corresponding to the basement rocks and the volcanic intrusions in the area. The analytic signal exhibited maxima over magnetization contrast, independent of the ambient magnetic field and source magnetization direction, location of these maxima thus determined the outlines of magnetic sources. Under the assumption that the anomalies were cause by vertical contacts, the method was used to estimate depth using a simple amplitude half width rule. The advantage of using analytic signal technique to determine magnetic parameters from magnetic anomalies is the independence of magnetization direction, thus the analytic signal will peak over the magnetic structure with local maxima over it edges. In addition, using the half width ratio method to determine depth to magnetic sources can avoid tedious operations with several characteristic points and reduce interference effects. An important aspect of this research was that the analytic signal peaks over the magnetic structure with local maxima over its edges (boundaries or contact), and the amplitude was simply related to magnetization, it had great importance in identifying dykes, contacts and intrusives over an area. For qualitative interpretation it may be preferable to have a function that produces highs over magnetic bodies. This can be partially achieved by first integrating the total field anomaly, and can be done in the frequency domain. The results can be used in drawing apparent magnetization maps and track $\mathrm{N}-\mathrm{S}$ contacts most especially at low latitude. Major information derived from analytic signal are (1) edge/contact determination, the analytic signal generates maxima over discreet bodies of edges and contacts, (2) source magnetization, the signal peak was proportional to the magnetization at that edge, (3) depth determination, this can be achieved from both inflection point and half width of the maximum anomaly. Results calculated from this research for the contact ranged from $1765.61-2622.46 \mathrm{~m}$, and for the dyke/sill it ranges from $3054.51-4536.85 \mathrm{~m}$ while that of horizontal cylinder ranges from 3985.01 - $5918.92 \mathrm{~m}$, the lowest values were from DD profiles, while the highs were from AA profiles, also the width of the highs are indicators to the depth of the contacts.

Conclusion: This study was carried out to determined depth from analytic signal which can be utilized to determine the depth to the magnetic sources utilizing the anomaly width at half the amplitude $\left(\mathrm{X}_{1 / 2}\right)$ to derive depths. From the geology of the area, the Cretaceous rocks may be up to 5 - $6 \mathrm{~km}$ thick, which agrees well with the calculated values from this study. An important aspect of this research was that the analytic signal peaks over the magnetic structure with local maxima over its edges (boundaries or contact), and the amplitude is simply related to magnetization.

\section{REFERENCES}

Abubakar, YI; Umegu, MN; Ojo, SB (2010). Evolution of Gongola Basin, Upper Benue Trough N.E Nigeria. Asian Journal. of Earth Sciences 1, $62-67$.

Alabi, AA; Makinde, V; Adewale, AO; Coker, JO; Aluko, TJ (2018). Estimation of magnetic Contact Location and Depth of Magnetic Sources in a sedimentary Formation. Mat. \& Geoenv. 66(4): $027-038$

Bassey, NE; Abubakar, SA; Ishiaku JM. (2012). Hill Slope Housing Development in Vinikilang, Yola, Nigeria. A Geo-disaster Risk. Journal of Earth Sciences and Geotechnical. Engineering. 2(1), 113-129.

Epuh, EE; Nwilo, PC; Olorode, DO; Ezeigbo, CU (2011). Basement Depth Estimation of the Gongola Basin Using Second Vertical Derivative Data as Input Anomaly Profile. Europ. J. Sci. Res. 61(1), 172.

Epuh, EE; Nwilo, PE; Olorode, DO; Ezeigbo, CU (2012). Multivariate Statistical Analysis of Gongola Basin Residual Gravity Anomalies for Hydrocarbon Exploration. J. Comp. \& Modeli. Int. ScI. Press. 2(1), $53-76$.

Epuh, EE; Nwilo, PE; Olorode, DO; Ezeigbo, CU (2014). Downward Continuation of Gongola 
Basin Residual Gravity Anomalies Using Density Log. J. Comp. \& Modeli. Int. Sci. Press 4(2), 122.

Haruna, IV; Ahmed, HA; Ahmed, AS (2012). Geology and Tectono-Sedimentary Disposition of the Bima Sandstone of the Upper Benue Trough (Nigeria): Implications for Sandstone-Hosted Uranium Deposits. J. Geol. \& Min. Res. 4(7), 168173.

Keating, P; Sailhac, P (2004). Use of the Analytic Signal to Identify Magnetic Anomalies due to Kimberlite Pipes. Geophy. 49(1), 180-190.

Kogbe C. A. 1981. Attempt to correlate the stratigraphic sequence of the Middle Benue Basin with those of the Anambra and Upper Benue Basin. Earth Evolutionary Science 2,139-143.

MacLeod, IN; Jones, K; Dai, FT (1993). 3-D Analytic Signal in the Interpretation of the Total Magnetic Field Data at low Magnetic Latitudes. Expl. Geophy. 24, 679-688
Mamman, YD; Dike, EFC; Haruna, IV; Haruna, AI (2010). Clay Mineralogy and Paleodepositional Environments of Late Cenomanian-Turonian Sediments in the Yola Arm, Upper Benue Trough, Northeastern Nigeria. J. Min. \& Geol. 46(1), 1-11.

Nabigian, MN (1984). Toward a Three Dimensional Automatic Interpretation of Potential Field Data via Generalized Hilbert Transform Fundamental Relations. Geophy. 47, 780-786.

Nabigian, M; Grauch, VJS; Hansen, RO; Lafehr, TR; Li, Y; Peirce, JW; Phillips, JD; Ruder, ME (2005). The Historical Development of the Magnetic Method in Exploration. Geophy. 70(6), 33-61.

Roest, WR;Verhoef, J; Pilkington, M (1992). Magnetic Interpretation Using the 3-D Analytic Signal. Geophy. 57, 116-125. 